\title{
A Novel Miniaturized Dual Slant-Polarized UWB Antenna Array with Excellent Pattern Symmetry Property for MIMO Applications
}

\author{
Zhi Zeng, ${ }^{1}$ Jianjun Huang, ${ }^{2}$ Zhaohui Song, ${ }^{3}$ and Qinyu Zhang ${ }^{1}$ \\ ${ }^{1}$ Shenzhen Graduate School, Harbin Institute of Technology, Shenzhen 518055, China \\ ${ }^{2}$ MOBI Antenna Technologies (Shenzhen) Co., Ltd., Shenzhen 518057, China \\ ${ }^{3}$ Harbin Institute of Technology, Harbin 150001, China \\ Correspondence should be addressed to Qinyu Zhang; zqy@hit.edu.cn
}

Received 30 June 2014; Accepted 4 September 2014

Academic Editor: Wenhua Chen

Copyright (C) 2015 Zhi Zeng et al. This is an open access article distributed under the Creative Commons Attribution License, which permits unrestricted use, distribution, and reproduction in any medium, provided the original work is properly cited.

\begin{abstract}
A novel miniaturized $1 \times 10$ uniform linear dual slant-polarized UWB antenna array for MIMO base station is presented. The antenna array operates in the frequency band from 1710 to $2690 \mathrm{MHz}$ with a $17.3-18.7 \mathrm{dBi}$ gain in a size of $105 \times 1100 \times 37 \mathrm{~mm}$. The array element is composed of two single-polarized dipoles evolved from bow-tie antenna with slots on them, which miniaturize the size of the antenna. The 10 array elements are fed through an air dielectric strip-line power splitter. Two parameters, the beam tracking and the beam squint, are presented to quantitatively describe the pattern symmetry property of the antenna. The simulated and measured radiation performances are studied and compared. The results show that the pattern symmetry property of the single antenna element has been improved about $24 \%$ compared with the former study, and the antenna array also provides excellent pattern symmetry property.
\end{abstract}

\section{Introduction}

Multiple-input multiple-output (MIMO) is the use of multiple antennas at both the transmitter and the receiver to improve communication performance [1]. MIMO has attracted attention in wireless communications, because it offers significant increases in data throughput and link range without additional bandwidth or increased transmit power [2]. It achieves this goal by spreading the same total transmit power over the antennas to achieve an array gain that improves the spectral efficiency and/or to achieve a diversity gain that improves the link reliability (reduced fading) [3]. Because of these advantages, MIMO is an important part of modern wireless communication standards such as IEEE $802.11 n$ (WIFi), 4G, 3GPP Long Term Evolution (LTE), WiMAX, and HSPA + [4]. While coding and signal processing are key elements to successful implementation of a MIMO system, the propagation channel and the antenna design represent major parameters that ultimately impact the system performance. As a result, considerable research has been devoted recently to these two areas. For example, assessing the potential of MIMO systems requires a new level of understanding concerning multipath channel characteristics. Furthermore, while we have extensive information concerning the behavior of an antenna in multipath channels [5], recent activity surrounding MIMO communications has exposed new issues related to the impact of antenna properties and the array configuration on the system performance. In [6], a simulation study of the channel capacity of a MIMO antenna system exploiting multiple polarizations was carried out, while in [7] Perez and Ibanez analyzed the capacity of MIMO systems based on dual-polarized antenna array.

In modern mobile telecommunications industry, dual slant-polarized $\left(+45^{\circ} /-45^{\circ}\right)$ base station antennas are widely used for their good anti-multi-path property. Usually, in a $2 \mathrm{G}$ network, a dual slant-polarized base station antenna works in 1T2R mode (1 of the 2 channels for transmitting, both 2 channels for receiving). In $3 \mathrm{G}$ or LTE network, both 2 channels of the dual slant-polarized base station antenna might be used to transmit and receive the signal. In this case, highly symmetric 


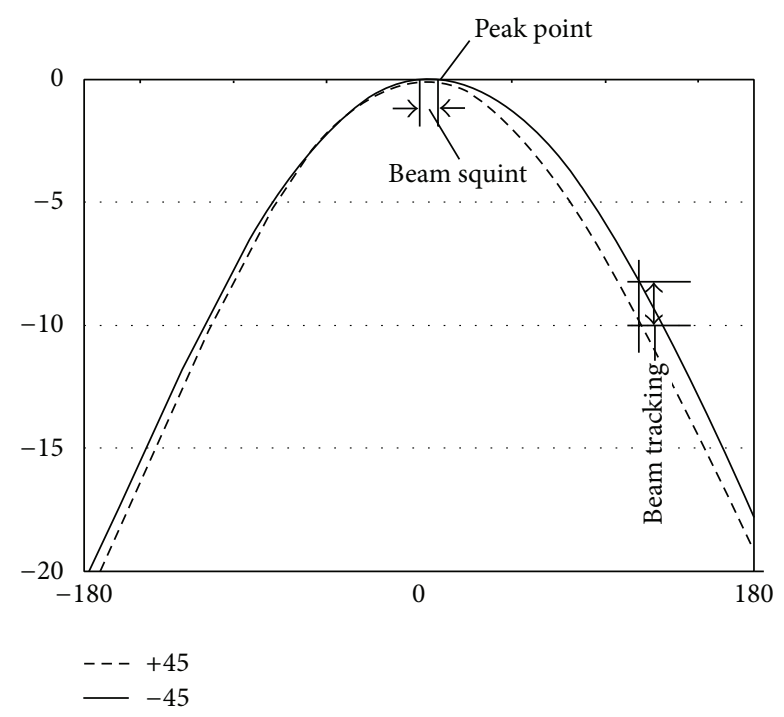

FIGURE 1: Antenna beam tracking and antenna beam squint.

radiation patterns are required to the dual slant-polarized base station antenna. However, only a few studies about the radiation pattern symmetry of the antenna were carried out in the past. In [8], Chair et al. studied 4 different types of dual-polarized dielectric resonator antennas and analyzed their radiation pattern symmetry qualitatively. In [9], Gao et al. presented a CPW-fed dual-polarized dielectric resonator antenna with "almost symmetrical" radiation patterns. In [10], Mak and Rowell presented a dual-polarized patch antenna with symmetrical patterns for base station in 1710$2690 \mathrm{MHz}$, but they did not analyze the pattern symmetry quantitatively either. In [11] Kim et al. proposed a modified dual-polarization horn antenna to improve radiation pattern symmetry and presented a method to evaluate the radiation pattern symmetry. They quantitatively analyzed the radiation pattern symmetry by comparing the normalized radiation pattern level of the E/H-plane at some specified angles including the $-10 \mathrm{~dB}$ beam width point. The smaller the differences, the better the radiation pattern symmetry. Both the simulated and measured results have shown that the radiation pattern level differences increase as the angle increases within the $-10 \mathrm{~dB}$ beam width range, so the difference at $-10 \mathrm{~dB}$ beam width point can be considered as a characteristic to describe the radiation pattern symmetry. In this paper, it is called the beam tracking, which is defined as the maximum level difference between the two orthogonal polarizations normalized radiation patterns at the $10 \mathrm{~dB}$ beam width point, as shown in Figure 1. The beam tracking can be expressed as

$$
\text { Beam tracking }=\max \left(\left|L_{-L}-L_{+L}\right|,\left|L_{-R}-L_{+R}\right|\right),
$$

where $L_{-L}$ is the level of $-45^{\circ}$ polarization at the $10 \mathrm{~dB}$ point on the left, $L_{+L}$ is the level of $+45^{\circ}$ polarization at the $10 \mathrm{~dB}$ point on the left, $L_{-R}$ is the level of $-45^{\circ}$ polarization at the $10 \mathrm{~dB}$ point on the right, and $L_{+R}$ is the level of $+45^{\circ}$ polarization at the $10 \mathrm{~dB}$ point on the right. The smaller the beam tracking is, the better the symmetry of the radiation pattern is. Ideally, the value of beam tracking is expected to be 0 , which means that the two patterns coincide completely at the $10 \mathrm{~dB}$ point. In [11], the authors supposed that the boresight was the axis of symmetry of the antenna. However, for most antennas, the boresight is not the symmetry axis of the antenna, because the beam is always tilted to one side, more or less. In this case only the amplitude is not enough to describe the radiation pattern symmetry, but also the angular dimension, the beam squint. The beam squint is defined as the ratio of the boresight angle to the $10 \mathrm{~dB}$ beam width;

$$
\text { Beam squint }=\frac{\text { boresight angle }}{10 \mathrm{~dB} \text { beam width }} .
$$

Ideally, the value of beam squint is expected to be 0 , which means that the boresight is just the symmetry axis of the antenna. The beam tracking and the beam squint describe the symmetric property of the dual-polarized antenna in the amplitude domain and the angular domain, respectively.

In this paper, a novel compact $1 \times 10$ dual slant-polarized antenna array with excellent pattern symmetry property is presented. The proposed antenna array operates in the frequency band from 1710 to $2690 \mathrm{MHz}$, with a size of 105 $\times 1300 \times 37 \mathrm{~mm}$. The fractional bandwidth of the antenna array is $44.5 \%$, which could be classified as ultra wideband (UWB) antenna according to the definition of UWB antenna by the Federal Communications Commission (FCC) and the International Telecommunication Union Radio (ITU-R) [12]. The simulations of the proposed antenna are performed using the commercial electromagnetic simulation software HFSS. In the whole range of $10 \mathrm{~dB}$ beam width, the worst beam tracking of the array element is $0.40 \mathrm{~dB}$, which has been improved about $24 \%$ compared with the result as $0.5398 \mathrm{~dB}$ in [11]. And the beam squint values are better than $1 \%$. The antenna array also provides excellent pattern symmetry property. A prototype of the proposed antenna array was fabricated and measured in an anechoic chamber. The experimental measurements concerning the antenna parameters are found to be in good agreement with the numerical results.

\section{Antenna Array Structure and Design}

2.1. Antenna Array Element. The pattern symmetry property of the antenna array is mainly decided by the properties of the array element, so the design of the array element is quite important. The geometry of the proposed antenna array element is shown in Figure 2. The dual slant-polarized array element is composed of 2 evolved bow-tie antennas on a $105 \mathrm{~mm}$ wide reflector, and the total height is $37 \mathrm{~mm}$. The evolutionary process from bow-tie antenna to the proposed array element is shown in Figure 3. The bow-tie antenna is a kind of antenna with two flaring, triangular shaped arms, which is a typical wide band antenna [13]. By adding slot on the arms, the equivalent electrical length of the arms is increased, so as to miniaturize the dimensions of the antenna. The array element has a strictly symmetrical structure, which is expected to obtain good radiation symmetry property. The feeding structure of the array element is shown in Figure 4. 


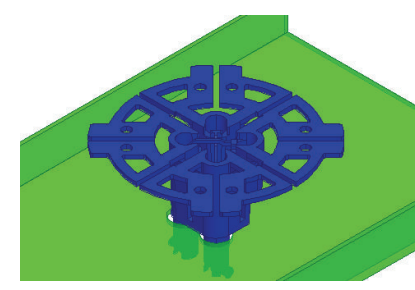

(a)

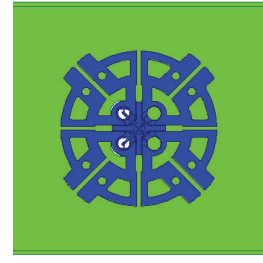

(b)

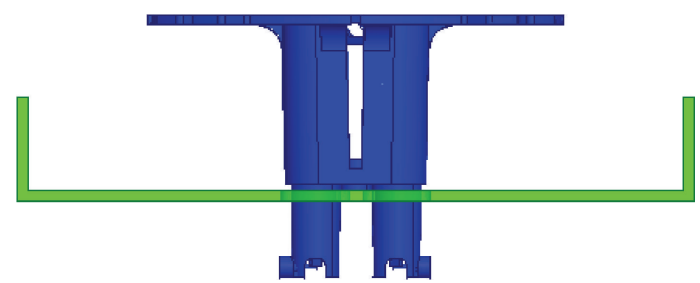

(c)

Figure 2: The geometry of the array element: (a) 3D view, (b) top view, (c) and side view.
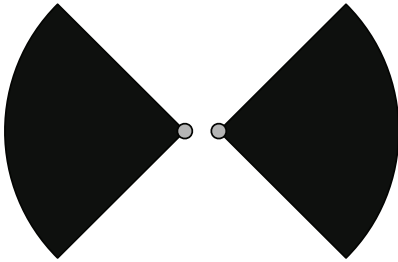

(a)

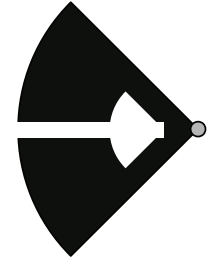

(b)

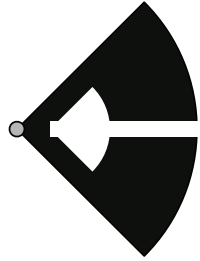

)

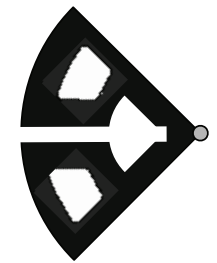

(c)

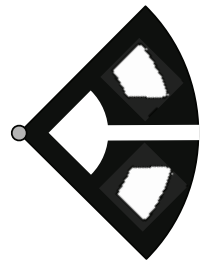

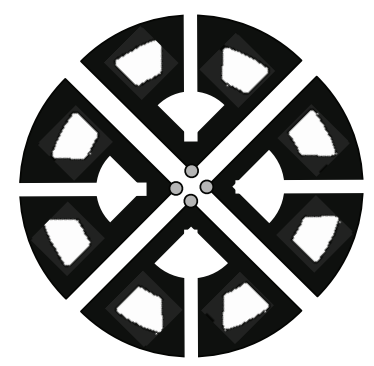

(d)

FIGURE 3: The evolution from bow-tie antenna to the proposed array element: (a) bow-tie antenna, (b) bow-tie antenna with slots, (c) bow-tie antenna with slots and holes, and (d) the proposed array element.

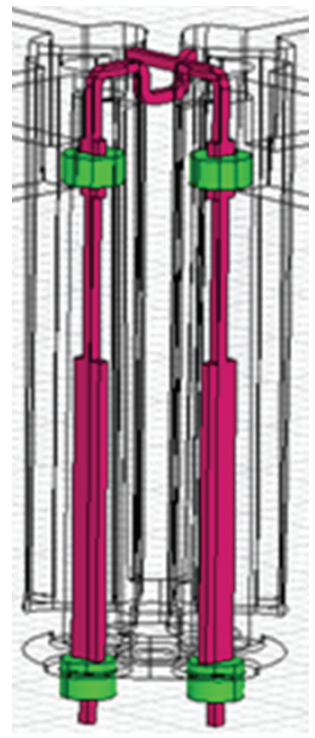

(a)

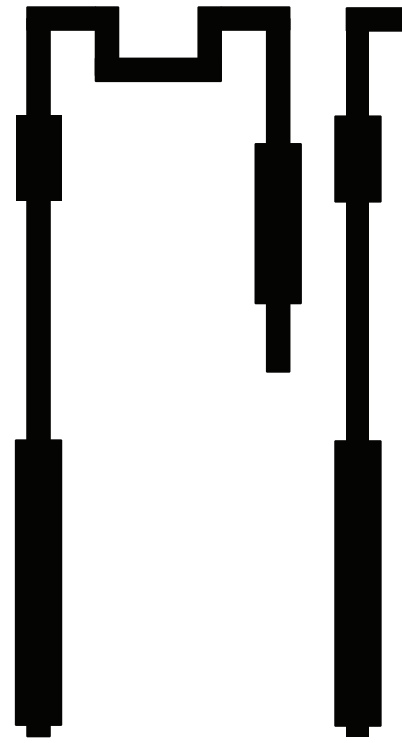

(b)

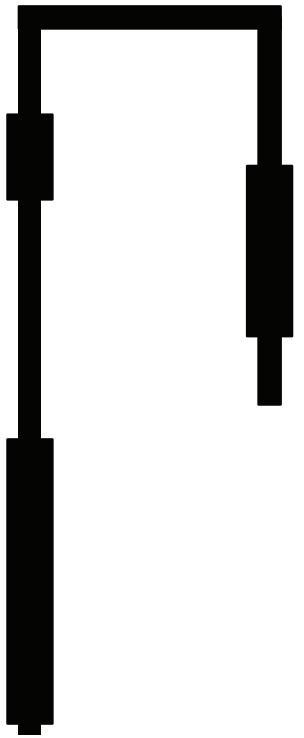

(c)

FIgURE 4: The feeding structure of the dipole: (a) 3D view, (b) the feeding structure for $-45^{\circ}$, and (c) the feeding structure for $+45^{\circ}$.

By adjusting the shape and the dimensions of the inner conductor, the antenna can be matched to $50 \Omega$ transmission lines in a bandwidth of $1710 \mathrm{MHz}-2690 \mathrm{MHz}$. Besides that, there are some holes in the arms and some raised blocks at the edge of the arms, which are brought in to tune the return loss over the whole frequency band.

2.2. Antenna Array. Based on the array element above, a uniform linear antenna array is designed. The proposed antenna array is composed of 10 elements, and the spacing between the elements was set to $110 \mathrm{~mm}$ based on the frequency characteristic. The structure of the antenna array is shown in Figure 5. The antenna array is fed by two 1 to 10 air dielectric strip-line power splitters, which are connected with the 10 elements through several coaxial cables as shown in Figure 6. The air dielectric strip-line has quite low transmission loss, which contributes to the gain of the antenna. The amplitude of each dipole could be conveniently adjusted by adjusting 


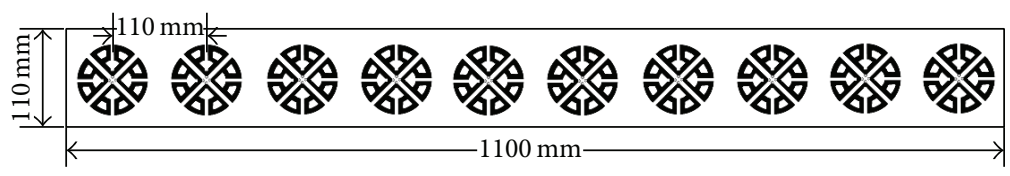

FIgURE 5: The structure of the antenna array.

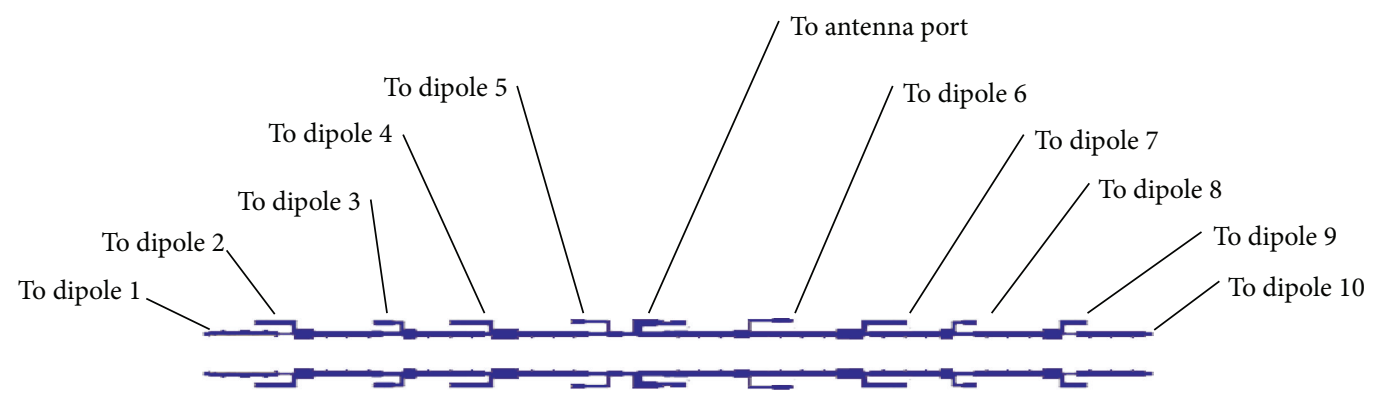

Figure 6: The feeding structure of the antenna array.

TABLE 1: The simulated beam tracking computed in H-plane and Eplane.

\begin{tabular}{lcccc}
\hline & \multicolumn{2}{c}{ H-plane } & \multicolumn{2}{c}{ E-plane } \\
$\begin{array}{l}\text { Freq. } \\
(\mathrm{MHz})\end{array}$ & $\begin{array}{c}\text { Element } \\
\text { beam } \\
\text { tracking }(\mathrm{dB})\end{array}$ & $\begin{array}{c}\text { Array beam } \\
\text { tracking } \\
(\mathrm{dB})\end{array}$ & $\begin{array}{c}\text { Element } \\
\text { beam } \\
\text { tracking }(\mathrm{dB})\end{array}$ & $\begin{array}{c}\text { Array beam } \\
\text { tracking } \\
(\mathrm{dB})\end{array}$ \\
\hline 1710 & 0.04 & 0.05 & 0.05 & 0.06 \\
2200 & 0.06 & 0.06 & 0.07 & 0.07 \\
2690 & 0.08 & 0.09 & 0.09 & 0.10 \\
\hline
\end{tabular}

the impedance of the corresponding matching section, and the phase of each dipole could be adjusted by adjusting the corresponding cable length. The dimensions of the antenna array are $105 \times 1100 \times 37 \mathrm{~mm}$.

\section{Antenna Array Simulation and Measurement}

A commercial electromagnetic simulation software HFSS is used to analyze the performance of the proposed antenna element and the antenna array. The weight of the amplitude and the phase of each element were optimized to achieve a low upper side lobe level, which is quite critical for a wireless telecommunication system base station. The antenna array has around 65 degrees beam-width in $\mathrm{H}$-plane, which is quite suitable for base station of mobile communication. The beam tracking and the beam squint of the array element and the antenna array are calculated in E-plane and H-plane. The simulated results of the beam tracking are shown in Table 1. The simulated beam squint results of the array element and the antenna array are shown in Tables 2 and 3, respectively. The simulated results show that both the proposed antenna element and the antenna array have quite good pattern symmetry property.
TABLE 2: The simulated beam squint of the array element.

\begin{tabular}{lcccc}
\hline \multirow{2}{*}{ Freq. (MHz) } & \multicolumn{2}{c}{ H-plane } & \multicolumn{2}{c}{ E-plane } \\
& $-45^{\circ}$ & $+45^{\circ}$ & $-45^{\circ}$ & $+45^{\circ}$ \\
\hline 1710 & $0.35 \%$ & $0.30 \%$ & $0.38 \%$ & $0.34 \%$ \\
2200 & $0.48 \%$ & $0.53 \%$ & $0.49 \%$ & $0.57 \%$ \\
2690 & $0.53 \%$ & $0.58 \%$ & $0.60 \%$ & $0.58 \%$ \\
\hline
\end{tabular}

TABLE 3: The simulated beam squint of the antenna array.

\begin{tabular}{lcccc}
\hline \multirow{2}{*}{ Freq. (MHz) } & \multicolumn{2}{c}{ H-plane } & \multicolumn{2}{c}{ E-plane } \\
& $-45^{\circ}$ & $+45^{\circ}$ & $-45^{\circ}$ & $+45^{\circ}$ \\
\hline 1710 & $0.35 \%$ & $0.32 \%$ & $0.39 \%$ & $0.34 \%$ \\
2200 & $0.50 \%$ & $0.55 \%$ & $0.49 \%$ & $0.58 \%$ \\
2690 & $0.56 \%$ & $0.59 \%$ & $0.61 \%$ & $0.60 \%$ \\
\hline
\end{tabular}

A prototype of the proposed antenna array was fabricated for measurement. The array elements were made of aluminum for its good processing property and coated with Tin to prevent the surface oxidation. The picture of the proposed antenna array prototype is shown in Figure 7, while the numerical and measurement results concerning the frequency behavior of the $S$ parameters of the antenna are reported in Figure 8.

The measurement of radiation patterns was carried out in an enclosed anechoic chamber. The simulated and the measured radiation patterns in $\mathrm{H}$-plane and E-plane are shown in Figures 9 and 10, respectively.

The simulated and the measured gain curves of the proposed antenna array are shown in Figure 11. However, the measured gain data of the antenna is approximately $0.1 \mathrm{~dB}$ below the predicted values in the operation frequency band. The reason for this behavior is probably coupling within the cable loss and/or the nonideal power distribution of the power dividers. 


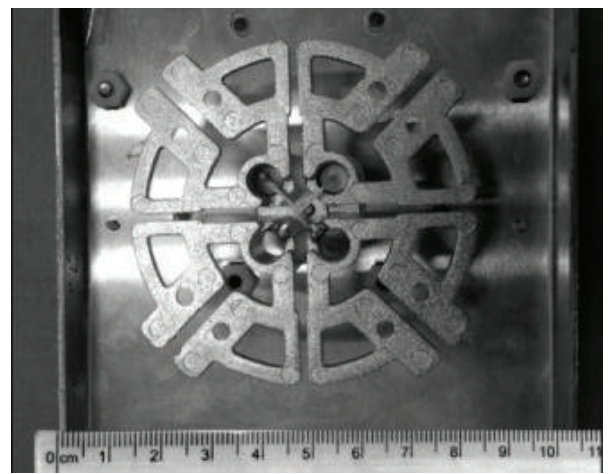

(a)

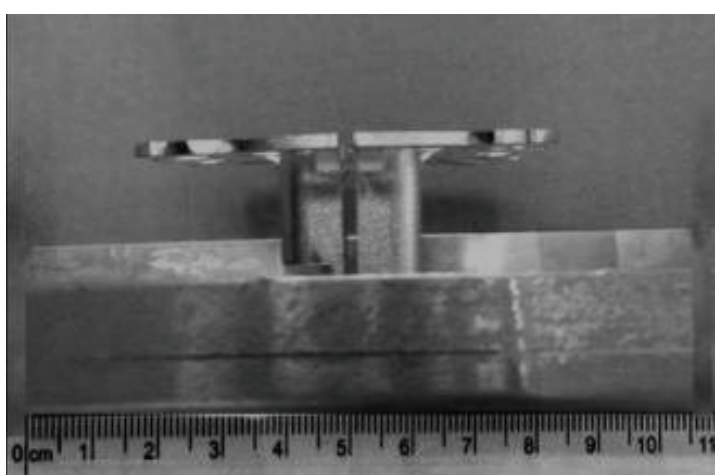

(b)

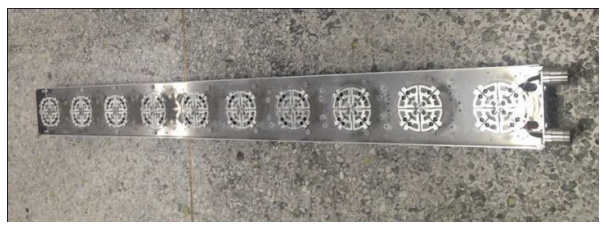

(c)

FIGURE 7: The photo of the proposed antenna array: (a) top view of the array element, (b) side view of the array element, and (c) the proposed antenna array.

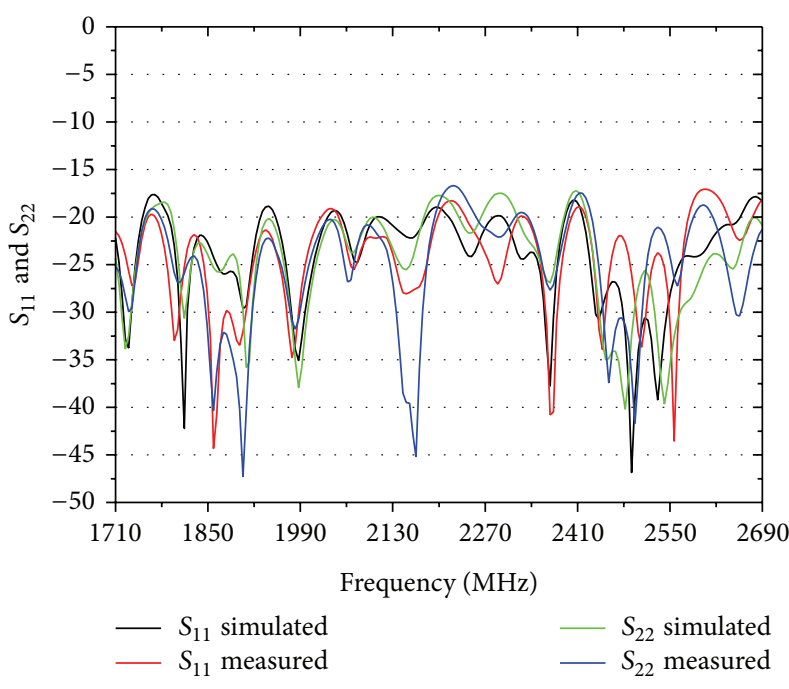

(a)

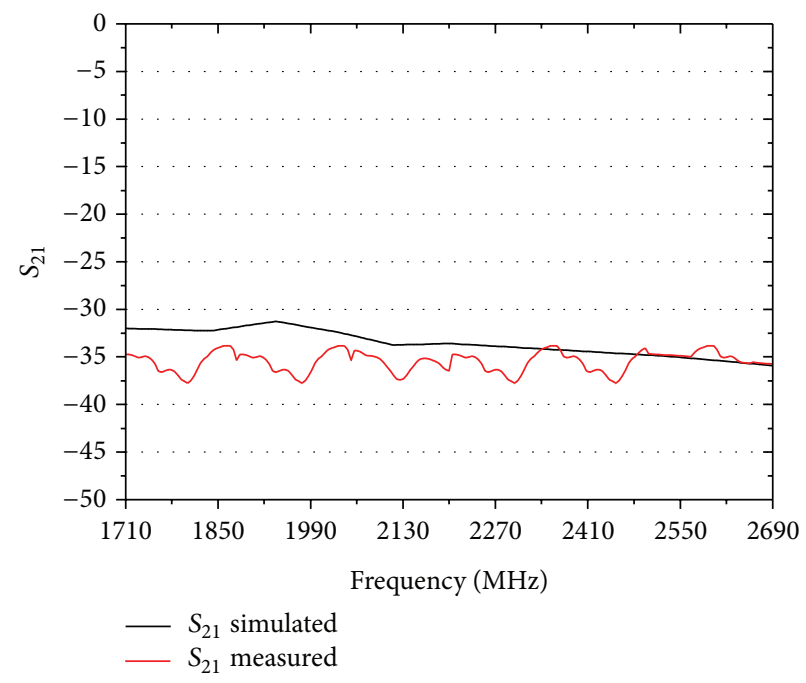

(b)

FIGURE 8: The simulated and measured $S$ parameters of the proposed antenna array: (a) $\left|S_{11}\right|$ and $\left|S_{22}\right|$ and (b) $\left|S_{21}\right|$.

The beam tracking and the beam squint of the array element and antenna array are measured in E-plane and $\mathrm{H}$ plane; the measured results of the beam tracking are shown in Table 4. The measured beam squint results of the array element and the antenna array are shown in Tables 5 and 6 , respectively. The measured array element beam tracking results are better than $0.40 \mathrm{~dB}$, which is about $24 \%$ better than the results as $0.5398 \mathrm{~dB}$ in [11]. And the measured antenna array beam tracking results are better than $0.41 \mathrm{~dB}$. Besides that, all the measured results of the beam squint are better than $1 \%$. The measured data agree very well with the numerical results and show attractive pattern symmetry characteristics for a MIMO base station.

\section{Conclusion}

In this paper, a novel compact $1 \times 10$ dual slant-polarized antenna array with excellent pattern symmetry property has been proposed. The antenna array is composed of 10 dual slant-polarized antenna array elements, which evolved from the bow-tie antennas. The antenna array operates in the frequency band $1710-2690 \mathrm{MHz}$, with a size 


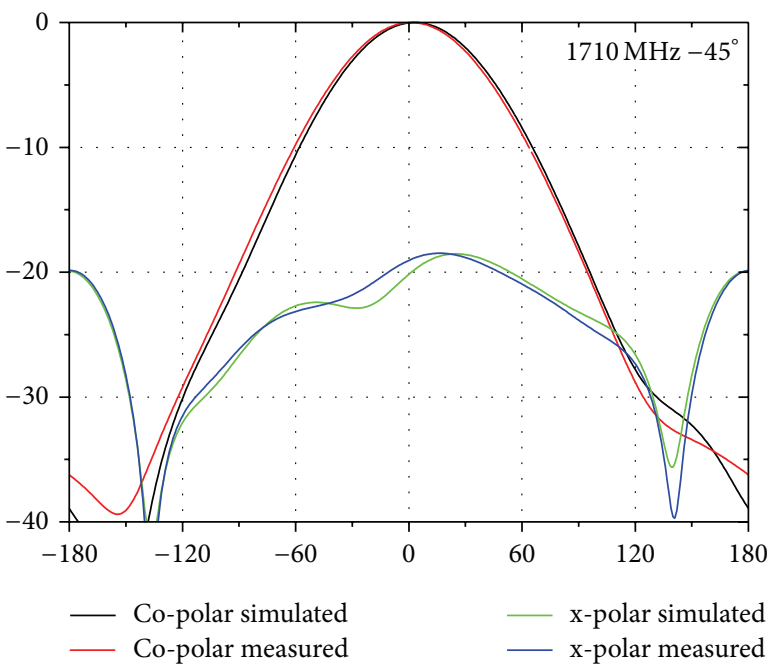

(a)
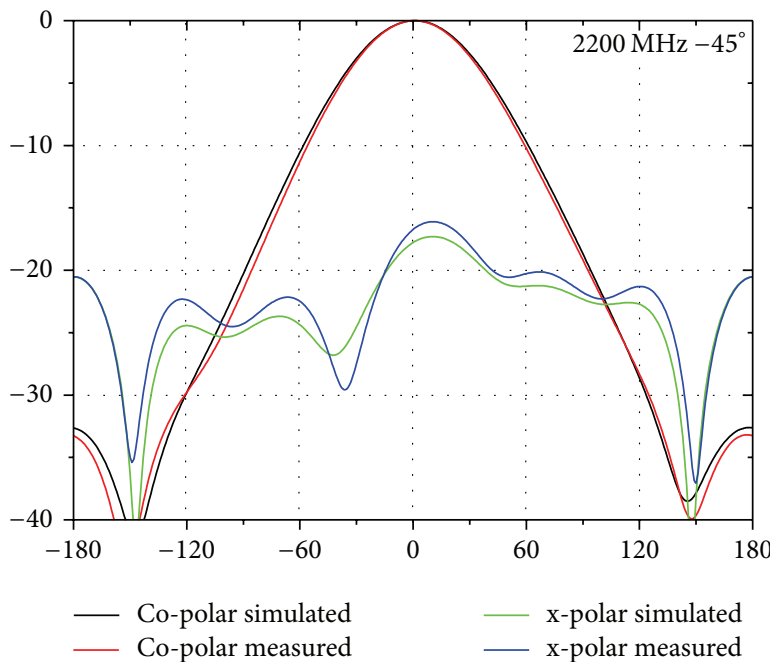

(c)

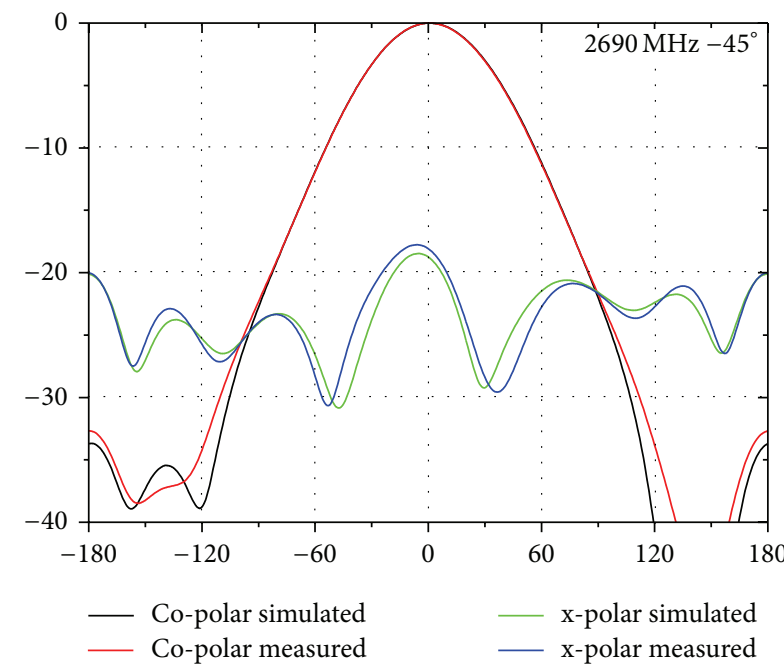

(e)

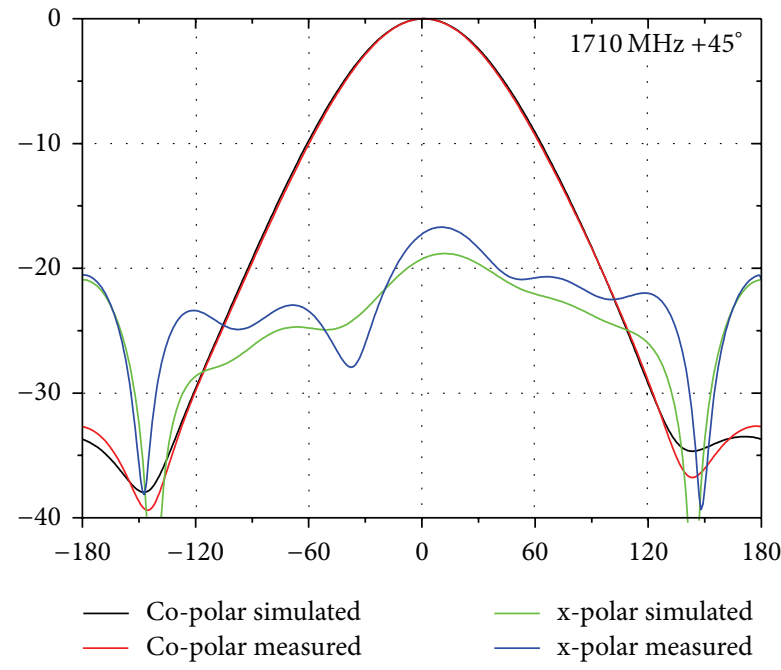

(b)

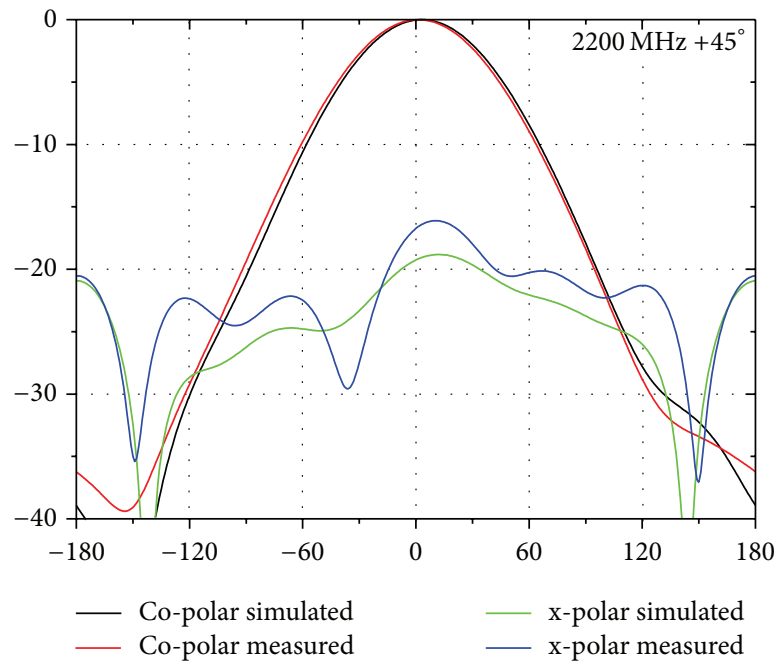

(d)

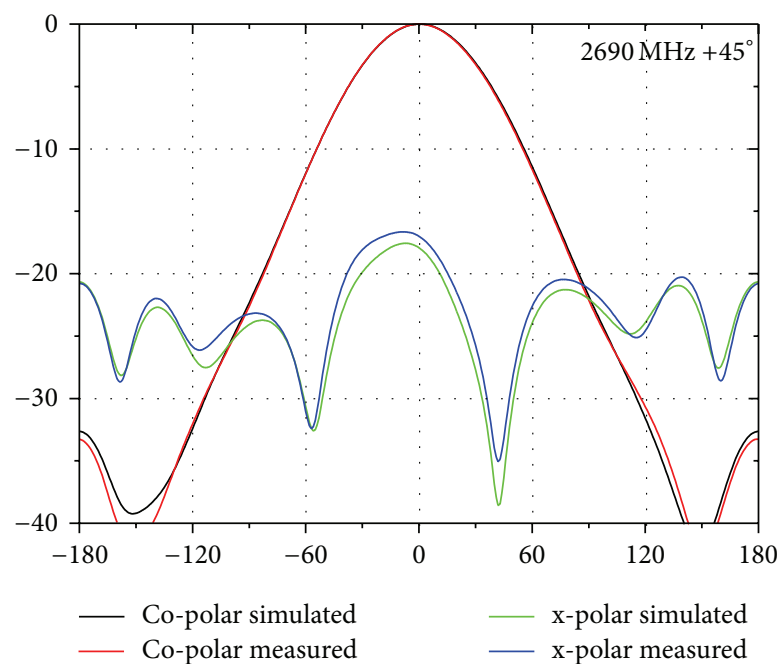

(f)

FIgURE 9: The simulated and measured radiation patterns in H-plane: (a) $1710 \mathrm{MHz}-45^{\circ}$, (b) $1710 \mathrm{MHz}+45^{\circ}$, (c) $2200 \mathrm{MHz}-45^{\circ}$, (d) $22000 \mathrm{MHz}+45^{\circ}$, (e) $2690 \mathrm{MHz}-45^{\circ}$, and (f) $2690 \mathrm{MHz}+45^{\circ}$. 


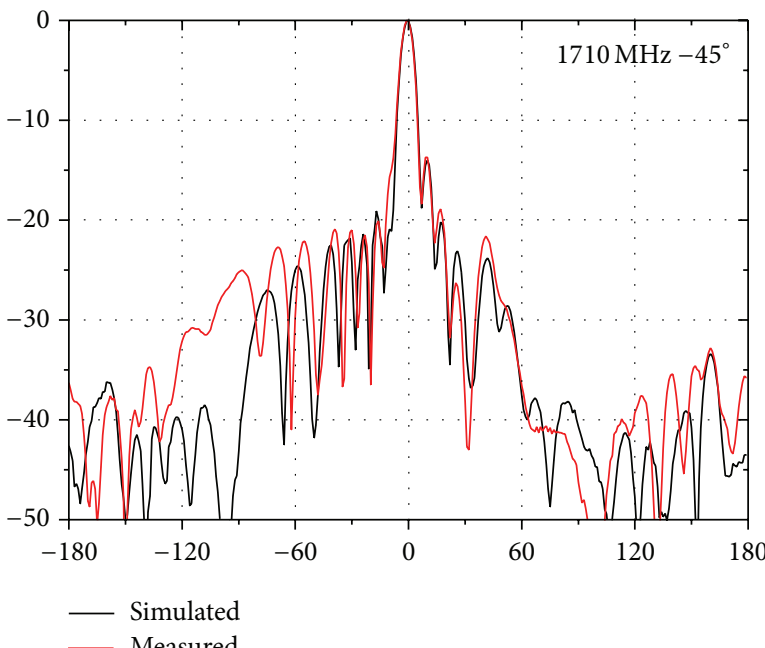

(a)

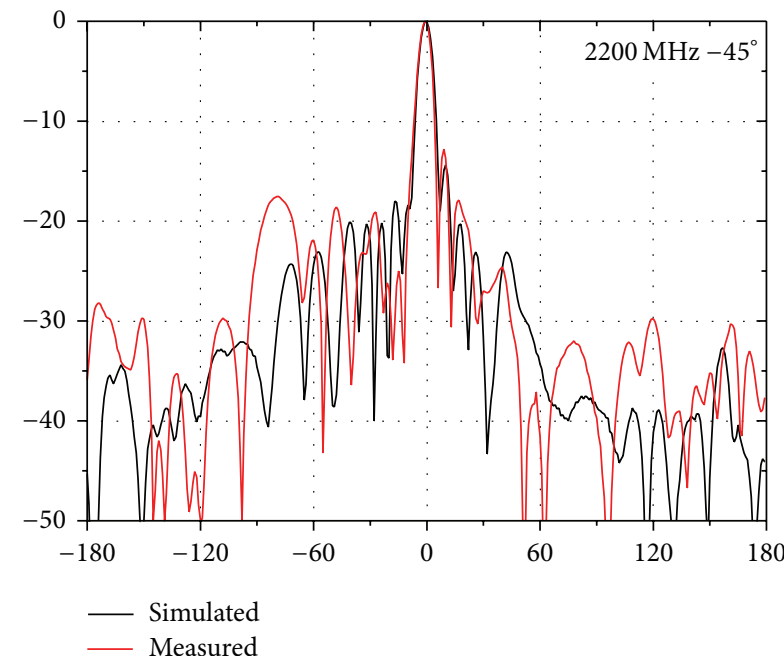

(c)

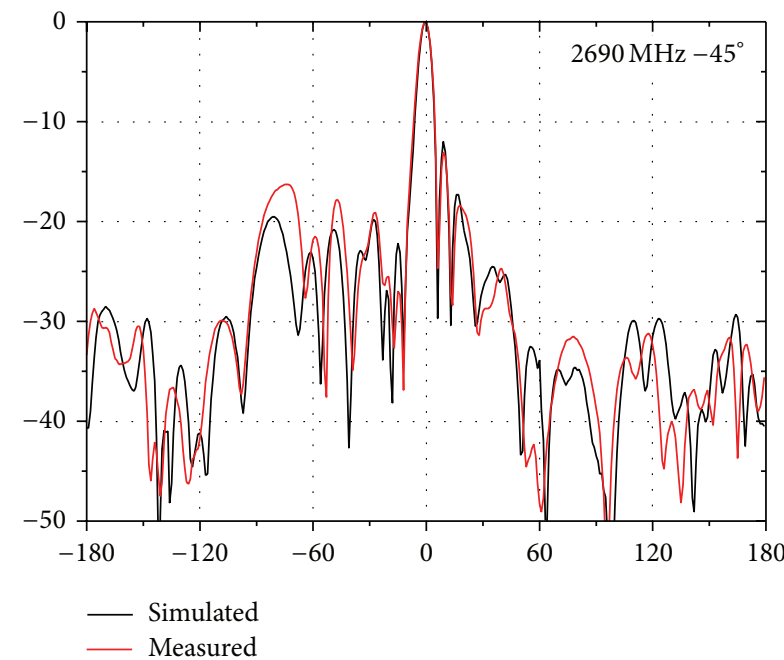

(e)

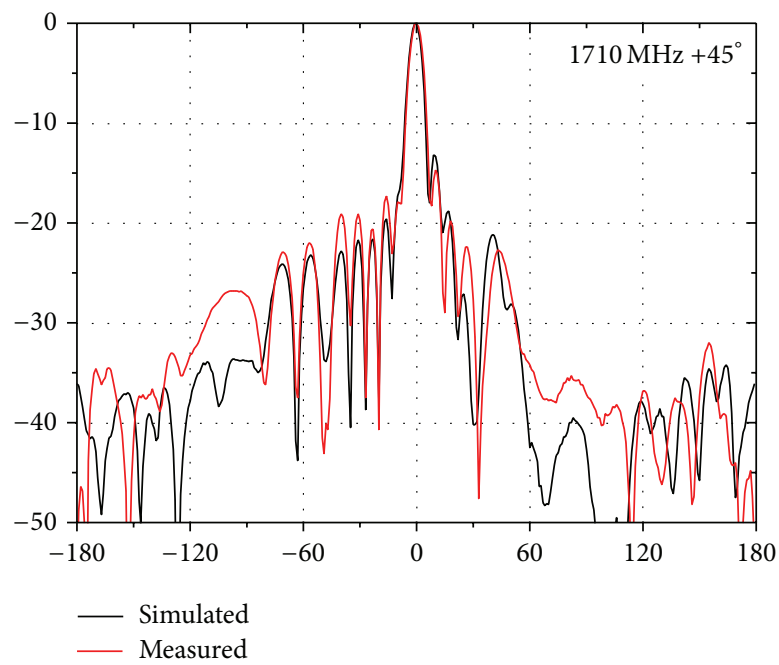

(b)

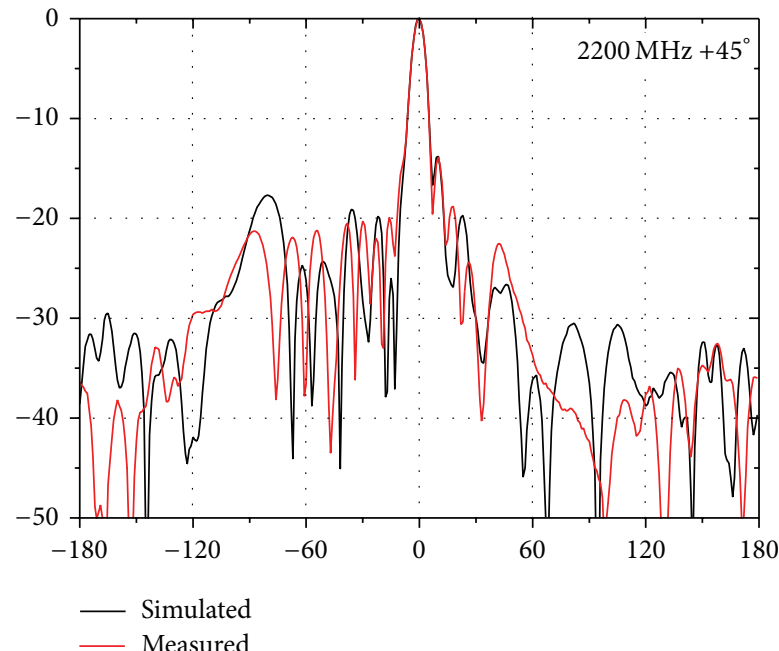

(d)

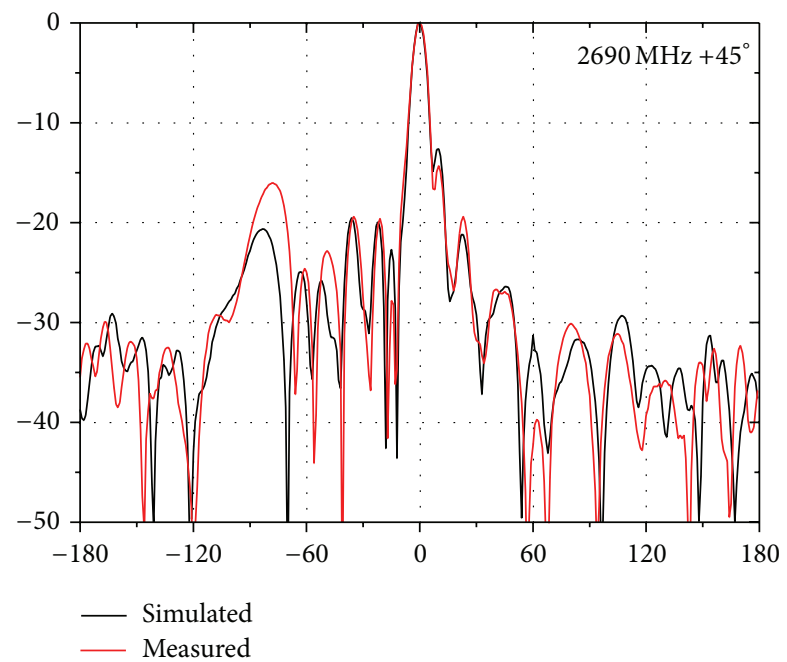

(f)

FIGURE 10: The simulated and measured radiation patterns in E-plane: (a) $1710 \mathrm{MHz}-45^{\circ}$, (b) $1710 \mathrm{MHz}+45^{\circ}$, (c) $2200 \mathrm{MHz}-45^{\circ}$, (d) $22000 \mathrm{MHz}+45^{\circ}$, (e) $2690 \mathrm{MHz}-45^{\circ}$, and (f) $2690 \mathrm{MHz}+45^{\circ}$. 


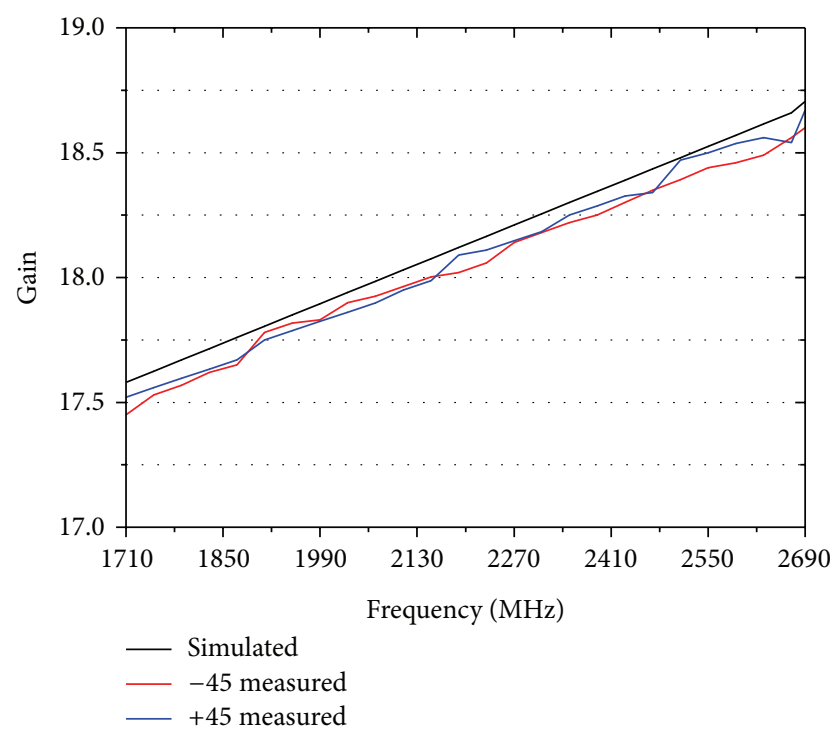

FIGURE 11: The gain of the proposed antenna array.

TABLE 4: The measured beam tracking computed in H-plane and Eplane.

\begin{tabular}{lcccc}
\hline $\begin{array}{l}\text { Freq. } \\
(\mathrm{MHz})\end{array}$ & $\begin{array}{c}\text { Element } \\
\text { beam } \\
\text { tracking }(\mathrm{dB})\end{array}$ & $\begin{array}{c}\text { Array beam } \\
\text { tracking } \\
(\mathrm{dB})\end{array}$ & $\begin{array}{c}\text { Element } \\
\text { beam } \\
\text { tracking }(\mathrm{dB})\end{array}$ & $\begin{array}{c}\text { Array beam } \\
\text { tracking } \\
(\mathrm{dB})\end{array}$ \\
\hline 1710 & 0.26 & 0.26 & 0.27 & 0.28 \\
2200 & 0.36 & 0.36 & 0.37 & 0.37 \\
2690 & 0.40 & 0.41 & 0.40 & 0.40 \\
\hline
\end{tabular}

TABLE 5: The measured beam squint of the array element.

\begin{tabular}{lcccc}
\hline \multirow{2}{*}{ Freq. (MHz) } & \multicolumn{2}{c}{ H-plane } & \multicolumn{2}{c}{ E-plane } \\
& $-45^{\circ}$ & $+45^{\circ}$ & $-45^{\circ}$ & $+45^{\circ}$ \\
\hline 1710 & $0.80 \%$ & $0.74 \%$ & $0.58 \%$ & $0.55 \%$ \\
2200 & $0.65 \%$ & $0.63 \%$ & $0.70 \%$ & $0.67 \%$ \\
2690 & $0.52 \%$ & $0.47 \%$ & $0.56 \%$ & $0.53 \%$ \\
\hline
\end{tabular}

TABLE 6: The measured beam squint of the antenna array.

\begin{tabular}{lcccc}
\hline \multirow{2}{*}{ Freq. (MHz) } & \multicolumn{2}{c}{ H-plane } & \multicolumn{2}{c}{ E-plane } \\
& $-45^{\circ}$ & $+45^{\circ}$ & $-45^{\circ}$ & $+45^{\circ}$ \\
\hline 1710 & $0.82 \%$ & $0.75 \%$ & $0.69 \%$ & $0.54 \%$ \\
2200 & $0.71 \%$ & $0.69 \%$ & $0.72 \%$ & $0.73 \%$ \\
2690 & $0.66 \%$ & $0.51 \%$ & $0.60 \%$ & $0.61 \%$ \\
\hline
\end{tabular}

of $105 * 1300 * 37 \mathrm{~mm}$ only. Two parameters, the beam tracking and the beam squint, that quantitatively describe the pattern symmetry, were presented. The results show that the pattern symmetry property of the single antenna element has been improved about $24 \%$ compared with the former study, and the antenna array also provides excellent pattern symmetry property.

\section{Conflict of Interests}

The authors declare that there is no conflict of interests regarding the publication of this paper.

\section{Acknowledgments}

The authors would like to express their sincere gratitude to MOBI Antenna Technologies (Shenzhen) Company for providing the software package of HFSS and antenna test chamber. This work was supported in part by the Key Program of the National Natural Science Foundation of China under Grant 61032003 and the National Basic Research Program of China under Grant 2009CB320402.

\section{References}

[1] J. F. Valenzuela-Valdés, M. A. García-Fernández, A. M. Martínez-González, and D. A. Sánchez-Hernández, "Evaluation of true polarization diversity for MIMO systems," IEEE Transactions on Antennas and Propagation, vol. 57, no. 9, pp. 2746-2755, 2009.

[2] P.-S. Kildal and K. Rosengren, "Correlation and capacity of MIMO systems and mutual coupling, radiation efficiency, and diversity gain of their antennas: simulations and measurements in a reverberation chamber," IEEE Communications Magazine, vol. 42, no. 12, pp. 104-112, 2004.

[3] K. S. Min, D. J. Kim, and M. S. Kim, "Multi-channel MIMO antenna design for WiBro/PCS band," in Proceedings of the IEEE International Symposium on Antennas and Propagation Society, pp. 1225-1228, Honolulu, Hawaii, USA, July 2007.

[4] M. A. Jensen and J. W. Wallace, "A review of antennas and propagation for MIMO wireless communications," IEEE Transactions on Antennas and Propagation, vol. 52, no. 11, pp. 28102824, 2004.

[5] J. Lee and N. Jindal, "Symmetrie capacity of MIMO downlink channels," in Proceedings of the IEEE International Symposium on Information Theory (ISIT '06), pp. 1031-1035, Seattle, Wash, USA, July 2006.

[6] L. Dong, H. Choo, R. W. Heath Jr., and H. Ling, "Simulation of MIMO channel capacity with antenna polarization diversity," IEEE Transactions on Wireless Communications, vol. 4, no. 4, pp. 1869-1873, 2005.

[7] J. Pérez, J. Ibáñez, L. Vielva, and I. Santamaría, "Capacity estimation of polarization-diversity MIMO systems in Urban microcellular environments," in Proceedings of the 15th IEEE International Symposium on Personal, Indoor and Mobile Radio Communications (PIMRC '04), vol. 4, pp. 2730-2734, September 2004.

[8] R. Chair, A. A. Kishk, and K. F. Lee, "Comparative study on different feeding techniques for dual polarized dielectric resonator antennas," in IEEE Antennas and Propagation Society International Symposium, pp. 2495-2498, Albuquerque, NM, USA, 2006.

[9] Y. Gao, Z. Feng, and L. Zhang, "Compact CPW-fed dielectric resonator antenna with dual polarization," IEEE Antennas and Wireless Propagation Letters, vol. 10, pp. 544-547, 2011.

[10] A. C. K. Mak and C. Rowell, "A low-cost dual-polarized wideband antenna," in Proceedings of the IEEE International Symposium on Antennas and Propagation Society, pp. 1478-1479, Orlando, Fla, USA, July 2013. 
[11] J. S. Kim, J. H. Yoon, Y. J. Yoon, W.-S. Lee, and C.-G. Kim, "Design of modified dual mode horn antenna to improve E/Hplane radiation pattern symmetry," in Proceedings of the 17th International Symposium on Antennas and Propagation (ISAP '12), pp. 547-550, Nagoys, Japan, November 2012.

[12] F. Gross, Frontiers in Antennas: Next Generation Design \& Engineering, McGraw-Hill, New York, NY, USA, 2011.

[13] E. A. Soliman, S. Brebels, P. Delmotte, G. A. E. Vandenbosch, and E. Beyne, "Bow-tie slot antenna fed by CPW," Electronics Letters, vol. 35, no. 7, pp. 514-515, 1999. 

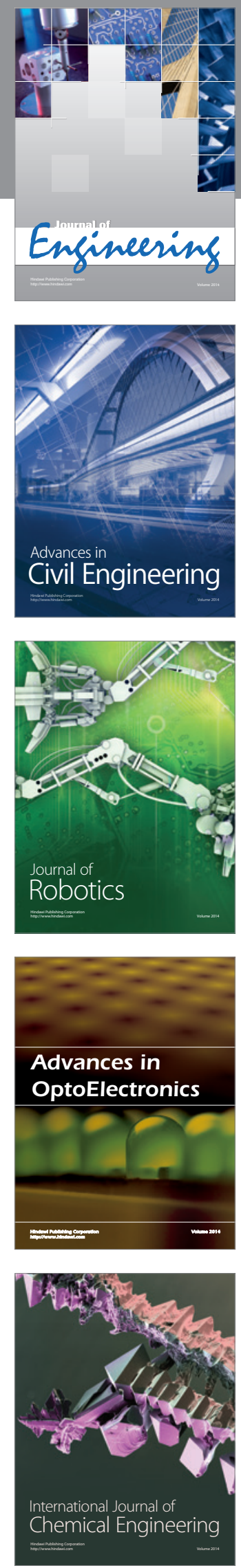

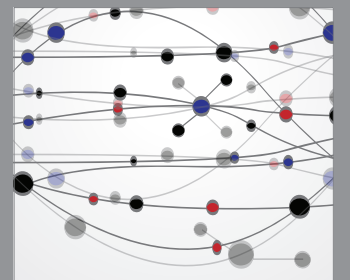

The Scientific World Journal
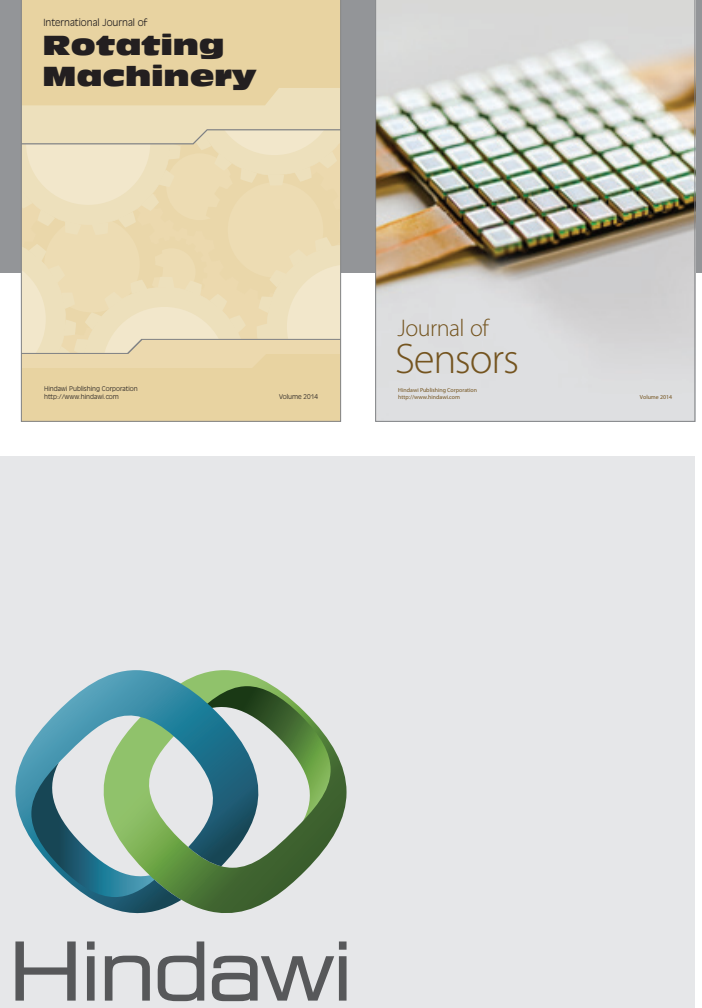

Submit your manuscripts at http://www.hindawi.com
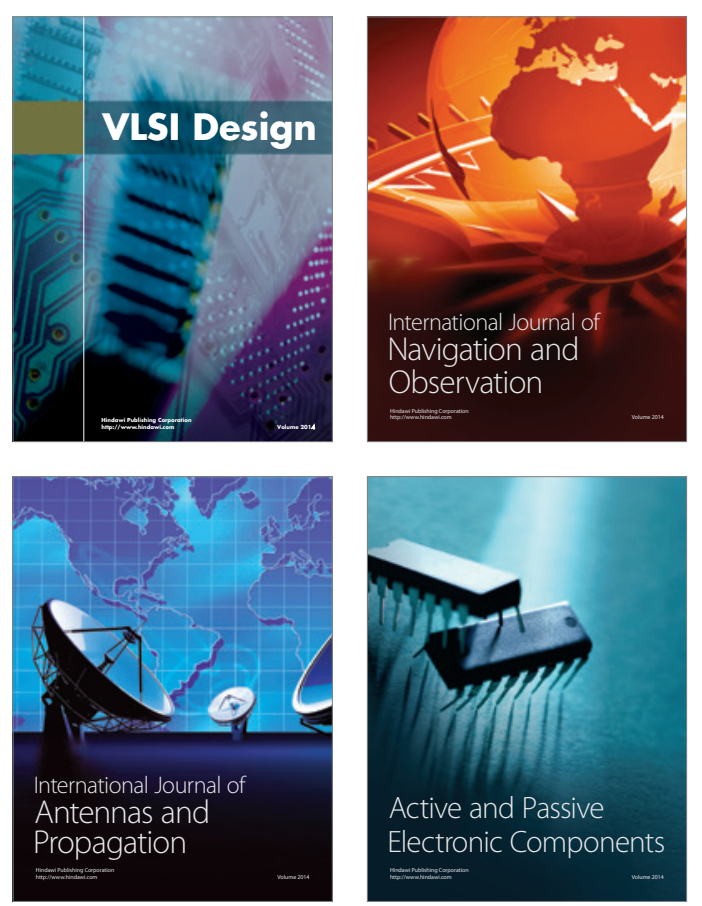
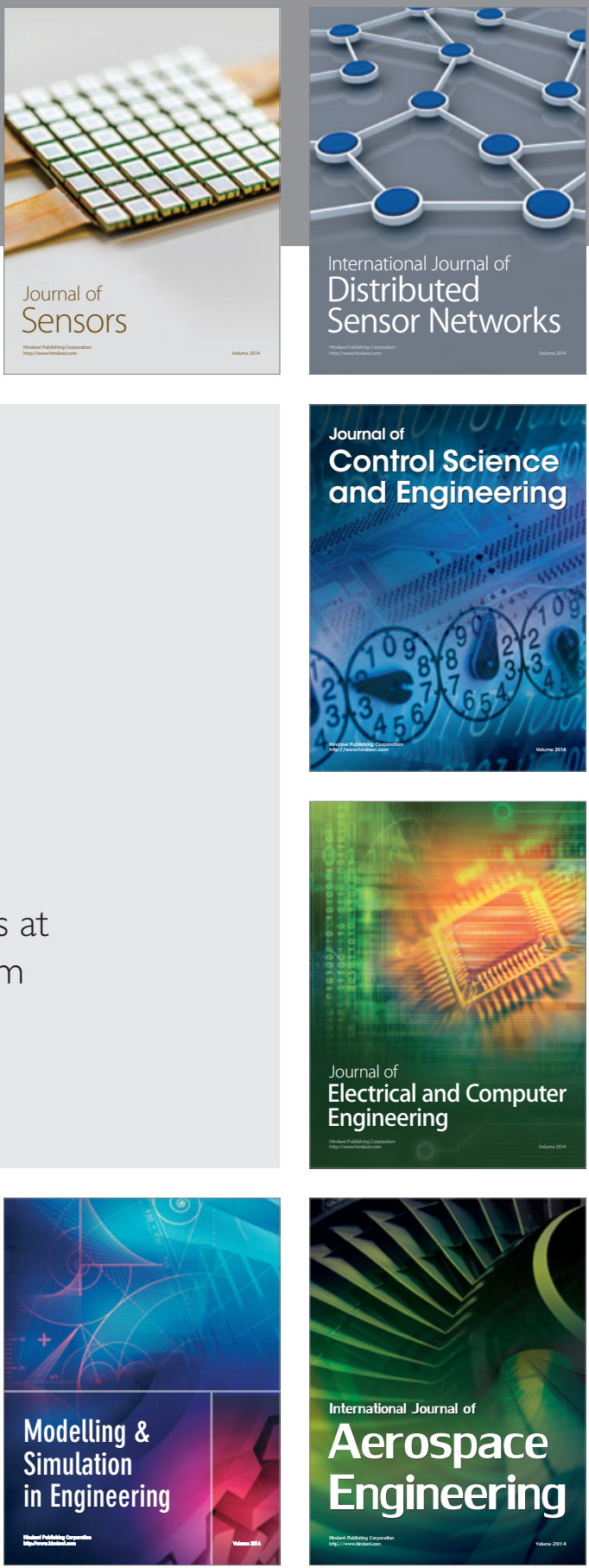

Journal of

Control Science

and Engineering
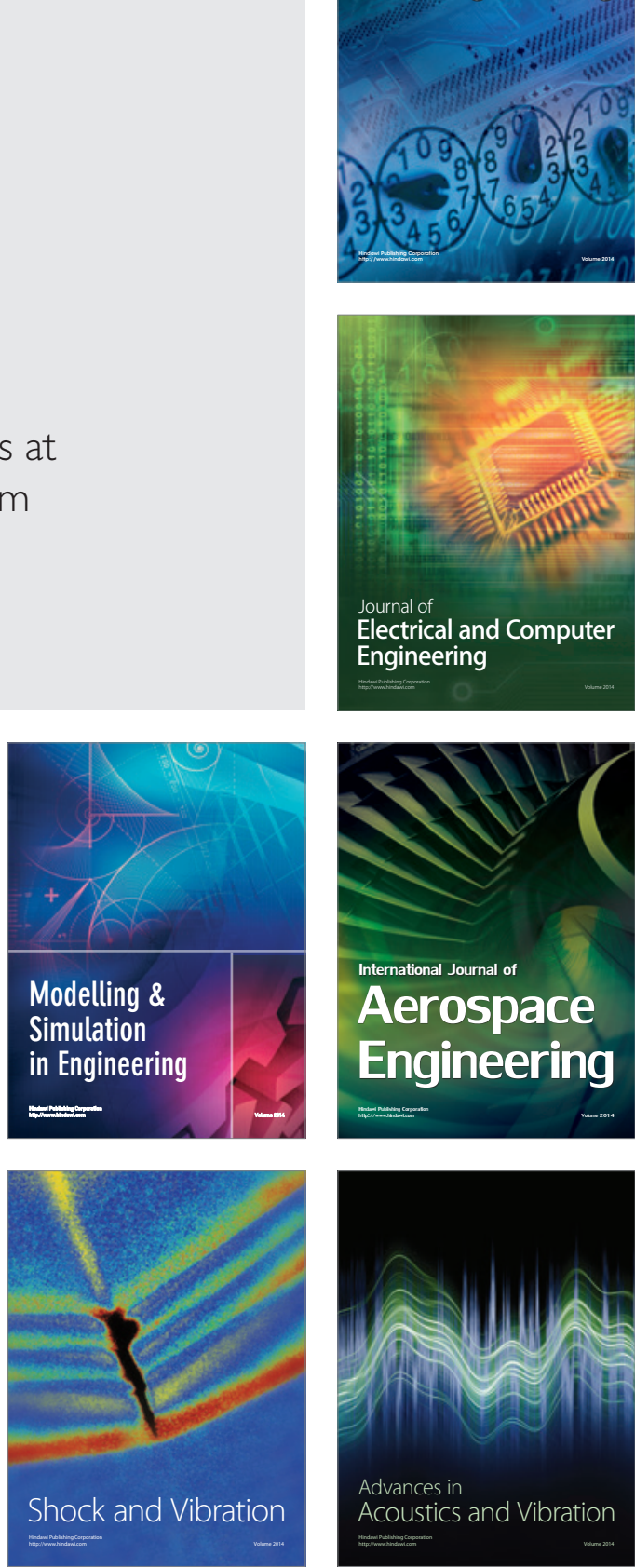